Supporting information:

\author{
A New Photosensitizer Based on Platinum (II) Terpyridyl Complex \\ for Hydrogen Evolution \\ Pingwu Du, Jacob Schneider, Paul Jarosz, Richard Eisenberg* \\ Department of Chemistry, University of Rochester, Rochester, New York 14627 \\ eisenberg@chem.rochester.edu
}

\title{
Synthesis of 1
}

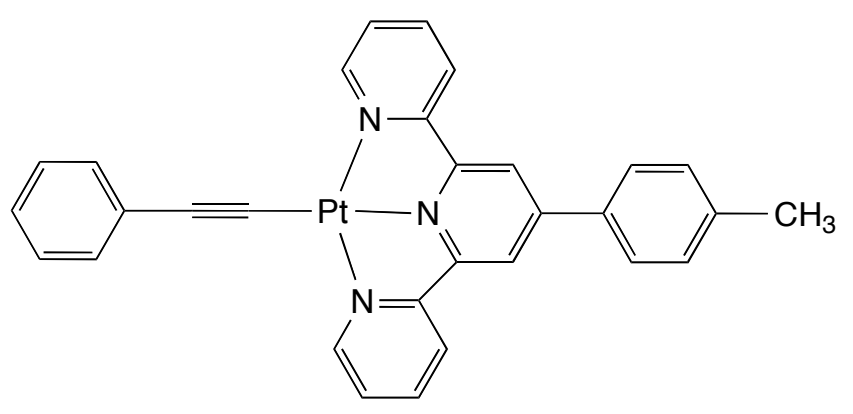

1

Complex 1 was prepared according to the literature method. Typically, 50mg of $[\mathrm{Pt}($ terpy $) \mathrm{Cl}] \mathrm{Cl}$ (terpy=4'-(4-tolylphenyl)-2,2,6',2"-terpyridine), $28 \mathrm{mg}$ of phenylacetylene, $5 \mathrm{mg}$ CuI was added in a mixture of $3 \mathrm{~mL}$ of DMF and $3 \mathrm{ml}$ of TEA (trimethylamine). The solution was sonicated for $8 \mathrm{~h}$ under nitrogen. Then $50 \mathrm{mg}$ of $\mathrm{NaClO}_{4}$ was added into the solution, which was sonicatd for extended $1 \mathrm{~h}$. Finally, $20 \mathrm{ml}$ deionized water was add into the solution. The precipitate was filtered out by frit and washed by water and ethyl ether. Yield: $83 \mathrm{mg}(75 \%)$ LC/MS: $\mathrm{m} / \mathrm{z}$ : calcd:619;found: $619 ;{ }^{1} \mathrm{H}$ NMR (400MHz, DMSO-d6 ): $\delta \quad$ (ppm) $2.44(\mathrm{~s}, 3 \mathrm{H})$, $7.20(\mathrm{~m}, 5 \mathrm{H}), 7.35(\mathrm{~d}, 2 \mathrm{H}) 7.46(\mathrm{t}, 2 \mathrm{H}), 7.62(\mathrm{~d}, 2 \mathrm{H}), 8.12(\mathrm{~m}, 4 \mathrm{H}), 8.22(\mathrm{~s}, 2 \mathrm{H}), 8.65$ (d, 2H).

\section{Emission quenching of 1 by TEOA and $\mathrm{MV}^{2+}$}

Since the solubility of $\mathbf{1}$, mixture of acetonitrile:water $=2: 3$ was chosen as the solvent. The solution of 1 shows strong emission band at $500-800 \mathrm{~nm}$ with $\lambda \quad \max =605 \mathrm{~nm}$. Before running the emission spectra, the sample was purged nitrogen for $15 \mathrm{~min}$. This emission band is readily quenched by both electron donor (TEOA) and electron acceptor $\left(\mathrm{MV}^{2+}\right)$. Figure 1 gives emission spectra by TEOA, which is reductive quenching and follows Stern-volmer activity (Figure 2). Figure 3 gives emission spectra by $\mathrm{MV}^{2+}$, which is oxidative quenching and also obeys the Stern-volmer equation (Figure 4).

\section{Photostability of 1}

The photostability of $\mathbf{1}$ in the reaction mixture was investigated by ${ }^{1} \mathrm{HNMR}$. After degassed, the samples were irradiated under 200W Mercury Xexon lamp. A cut filter was used to cut off the light below $410 \mathrm{~nm}$. For reductive quenching, the $\mathrm{Pt}$ 
chromophore and TEOA were dissolved in $\mathrm{CD}_{3} \mathrm{CN}: \mathrm{D}_{2} \mathrm{O}=4: 1$ solvent. The degassed sample was irradiated for over 10 hours. From ${ }^{1} \mathrm{HNMR}$ information (Figure 5), there is no damage for characteristic peaks of complex 1 between 7.0-9.0ppm, which means 1 is stable upon reductive quenching. But there is a new peak appeared at $9.60 \mathrm{ppm}$. The characteristic peaks of TEOA become in a mess at low field.For oxidative quenching process with $\mathrm{MV}^{2+}$, the degassed sample was irradiated under the same conditions as reductive quenching. There is no any considerable change for both $\mathrm{Pt}$ chromophore and $\mathrm{MV}^{2+}$, which indicates 1 is also stable upon oxidative quenching (Figure 6).

\section{Hydrogen Production}

For photoinduced hydrogen evolution, each sample was made in a $50 \mathrm{~mL}$ roundbottom flask with volume of $25 \mathrm{ml}$ in acetonitrile:water $=2: 3$. Typically, the sample contains $2.23 \times 10^{-5} \mathrm{M}$ photosensitizer, $6 \times 10^{-5} \mathrm{M}$ Pt colloids. A series of $\mathrm{pH}$ buffer were phosphate buffer. The flask was sealed by suba-seal and degassed by bubbling nitrogen for $15 \mathrm{~min}$ under atomosphore pressure at room temperature. Then the sample was degassed under vacuum and added nitrogen (760Torr) into headspace of flask. After that, $5 \mathrm{ml}$ nitrogen was took out of the flask and $5 \mathrm{ml}$ methane (760Torr) was injected into the flask, which serve as the internal standard. The samples were irradiated under 200W Mercury Xexon lamp. A cut filter was used to cut off the light below $410 \mathrm{~nm}$. The hydrogen amount was measured by GC-17A (Shimadzu) with a molecular $5 \AA$ column $(30 \mathrm{~m} \times 0.53 \mathrm{~mm})$.

Control experiments were run under the same conditions as hydrogen evolution except taking out one of the reaction species. The results are in chart 1. 


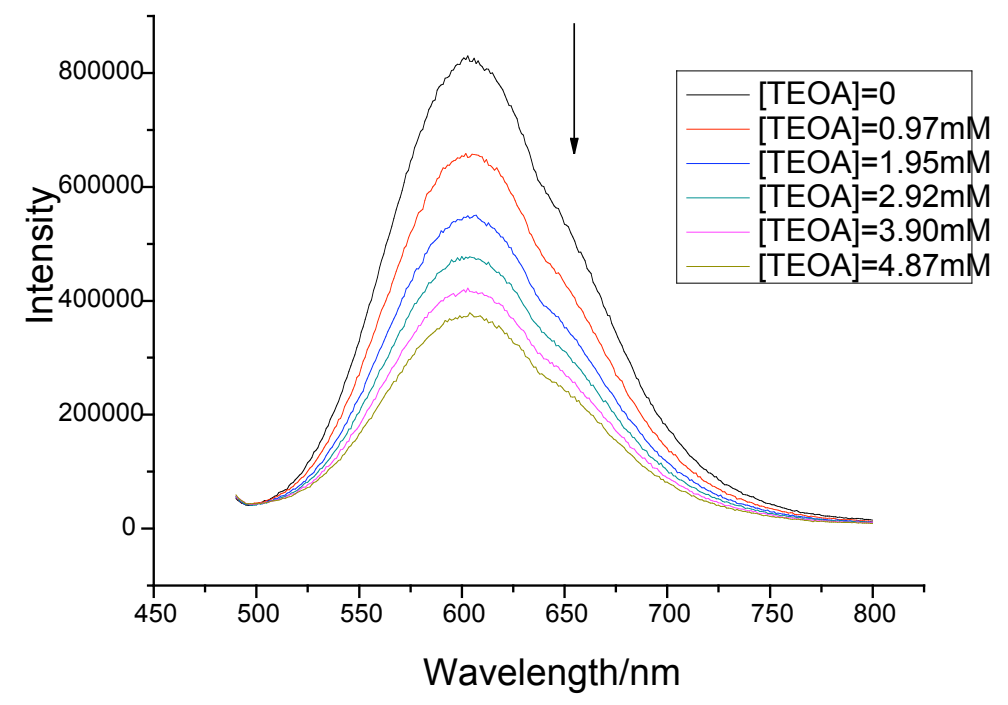

Figure 1. Emission spectra of $\mathbf{1}$ by changing the concentration of TEOA. The concentration of 1 was $2.23 \times 10^{-5} \mathrm{M}$ 


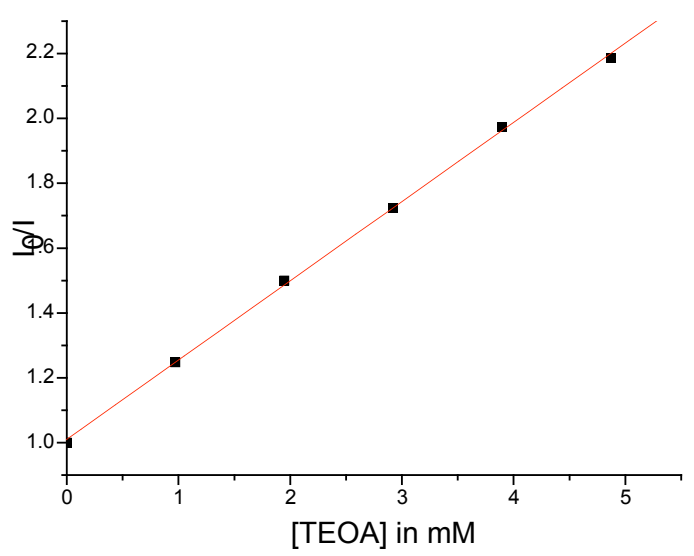

Figure 2. Stern-Volmer plot for emission quenching of $\mathbf{1}$ by TEOA 


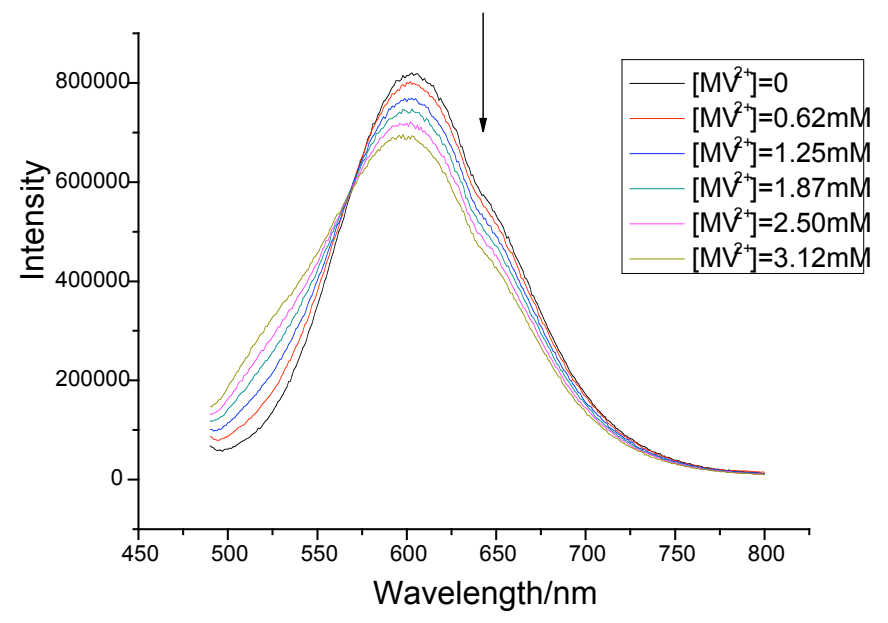

Figure 3. Emission spectra of $\mathbf{1}$ by changing the concentration of $\mathrm{MV}^{2+}$. The concentration of 1 was $2.23 \times 10^{-5} \mathrm{M}$ 


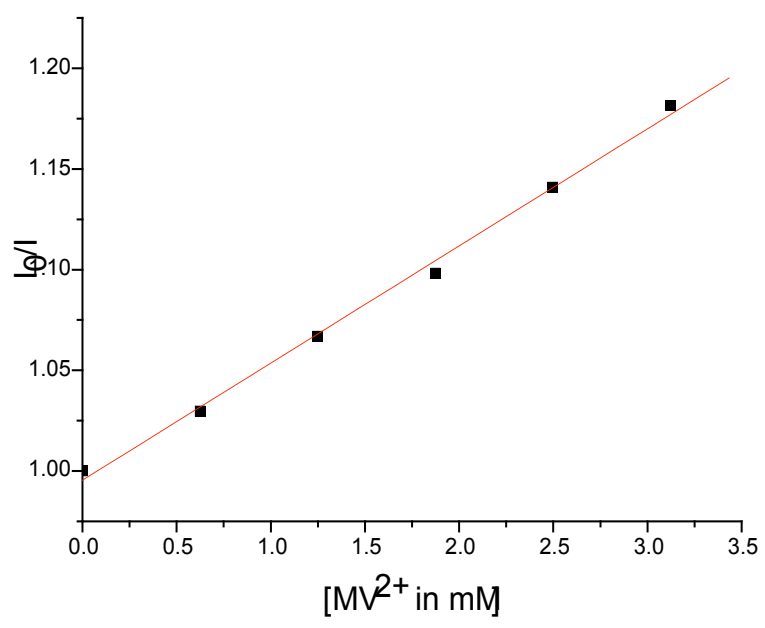

Figure 4. Stern-Volmer plot for emission quenching of $\mathbf{1}$ by $\mathrm{MV}^{2+}$ 


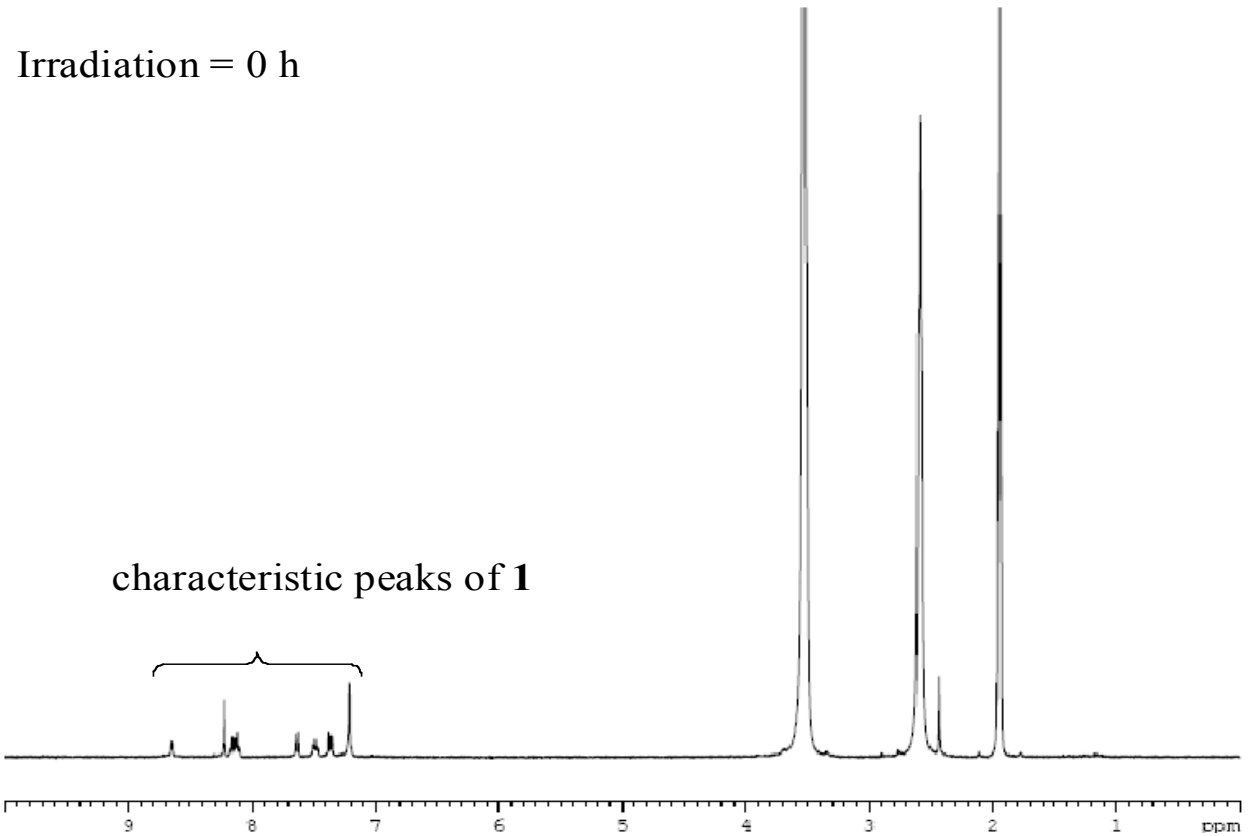

Irradiation $=10 \mathrm{~h}$

new peak characteristic peaks of $\mathbf{1}$

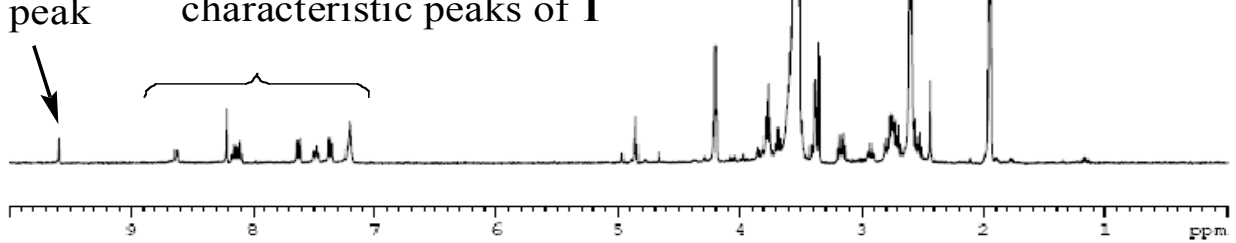

Figure 5. ${ }^{1}$ HNMR for checking the photostability of photosenzitizer in the degassed mixture of TEOA and $\mathbf{1}$ upon irradiation 

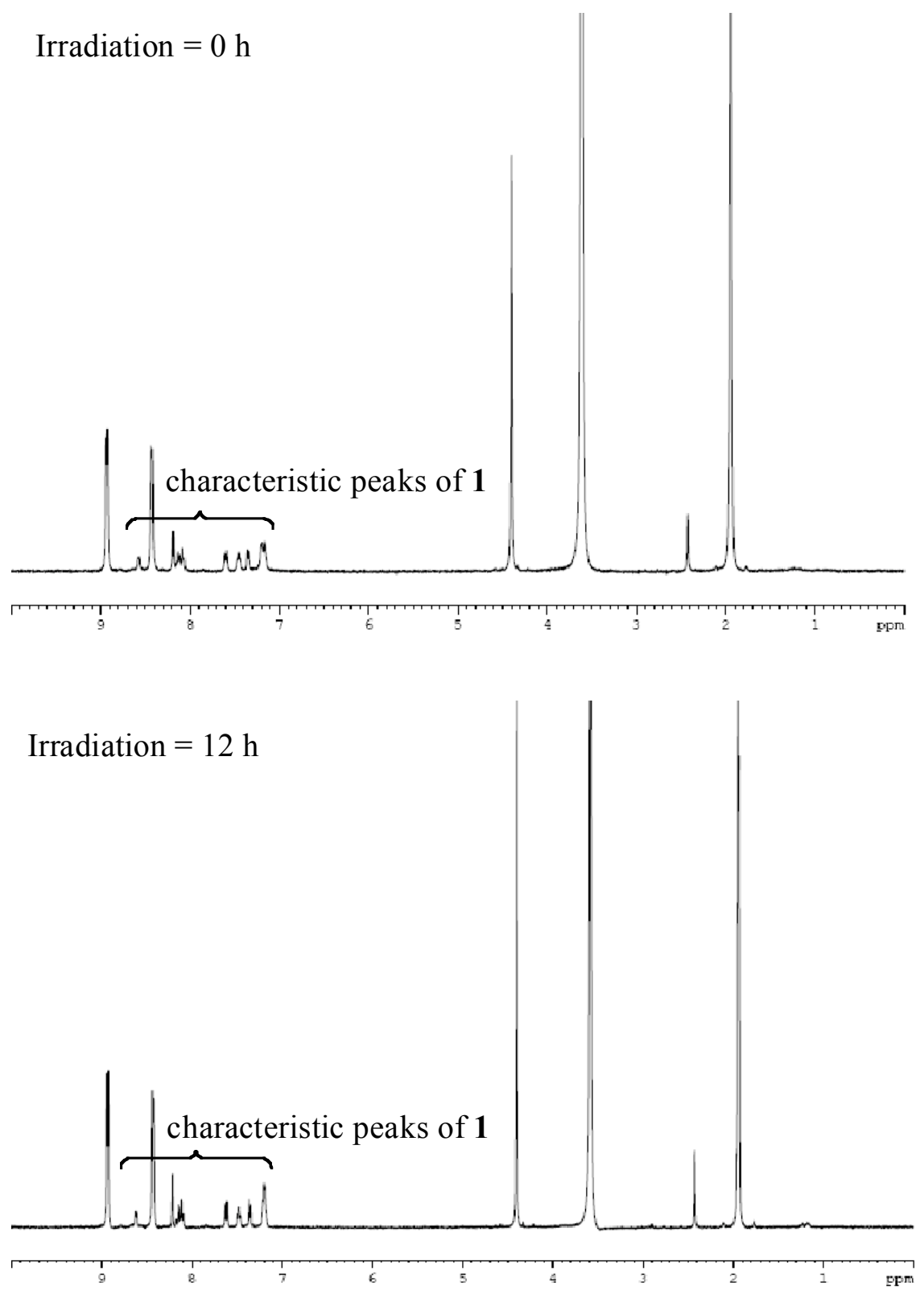

Figure $6 .{ }^{1}$ HNMR for checking the photostability of photosenzitizer in the degassed mixture of $\mathrm{MV}^{2+}$ and $\mathbf{1}$ upon irradiation 
Chart 1. Control experiments of hydrogen evolution (irradiation of $3 \mathrm{~h}$ for every experiment)

\begin{tabular}{|c|c|c|c|c|}
\hline \multicolumn{4}{|c|}{ Reaction species } & \multirow[t]{2}{*}{ Product $\left(\mathrm{H}_{2}\right)$} \\
\hline Photosensitizer & TEOA & $\mathrm{MV}^{2+}$ & Pt colloids & \\
\hline Yes & Yes & Yes & Yes & Yes \\
\hline No & Yes & Yes & Yes & No \\
\hline Yes & No & Yes & Yes & No \\
\hline Yes & Yes & No & Yes & No \\
\hline Yes & Yes & Yes & No & No \\
\hline
\end{tabular}

